\title{
Balıkların Başlıca Bakteriyel Zoonozları
}

\author{
İlker Hanci ${ }^{1}$, Ertan Emek Onuk ${ }^{2}$ \\ ${ }^{1}$ Sinop Il Gıda Tarım ve Hayvancılık Müdürlüğ̈̈, Sinop \\ ${ }^{2}$ Ondokuz Mayıs Üniversitesi Veteriner Fakültesi, Su Ürünleri Hastalıklarl Anabilim Dalı, Samsun
}

Geliş Tarihi / Received: 05.09.2016, Kabul Tarihi / Accepted: 23.10.2016

\begin{abstract}
Özet: Son yıllarda su içerisindeki yaşamın hızlı bir şekilde endüstriyel bir sanayi dalı olarak gelişmesi ve buna bağlı olarak yoğun yetiştiricilik şartlarında yapılan üretimin artması enfeksiyöz hastalıkların görülme sıklığını arttırmaktadır. Özellikle, akuakültürde görülen bazı bakteriyel enfeksiyonların zoonoz potansiyele sahip olması bu hastalıkları halk sağlığı açısından önemli kılmaktadır. Bu derlemede hem balıklarda hem de insanlarda enfeksiyon oluşturan başlıca bakteriyel zoonotik ajanlar hakkında literatür bilgilerine yer verilmiştir.
\end{abstract}

Anahtar kelimeler: Bakteriyel zoonoz, balık

\section{Main Bacterial Zoonoses of Fish}

\begin{abstract}
In recent years, due to the development of life in water as an industrial branch and increase in aquaculture production under intensive culture conditions have lead to increase in incidence of infectious diseases. Particularly some bacterial infections which appear in aquaculture are important for public health due to their zoonotic potential. This review includes literature information about major bacterial zoonoses causeing infection both in fish and human.
\end{abstract}

Key words: Bacterial zoonose, fish

\section{Giriş}

Nüfusun ve beslenme sorunlarının hızla arttığ 1 dünyada, zengin bir protein kaynağı olan su ürünlerine olan talep giderek artmaktadır. Su ürünleri stoklarından ekonomik ve sürekli olarak yararlanmak için kaynakların korunarak üretiminin devamlılığının sağlanması gerekmektedir. Bu nedenle yetiştiricilik yoluyla mevcut su ürünleri üretiminin arttırılmasına yönelik çalışmalar, gelişmiş ve gelişmekte olan ülkelerde giderek artmaktadır [49]. Bununla birlikte yoğun balık üretiminin doğal ve insan eliyle yapılmış akuatik ortamların kontamine olmasına neden olabileceği ve bu durumun sadece balık sağlığını etkilemediği aynı zamanda insan tüketimine sunulan balıklar ile ilgili güvenlik endişelerini artırdığ bildirilmektedir [41]. Verilere göre ülkemiz su ürünleri sektörünün de hızlı bir gelişim sürecine girdiği ve su ürünleri yetiştiriciliği ile sağlanan ürün miktarının her yıl arttı̆̆ görülmektedir. 2014 y1lında bir önceki yıla oranla yetiştiricilik yoluyla elde edilen ürün miktarında $\% 0,7$ 'lik bir artış gerçekleşmiş ve toplam üretim 235 bin 133 tona ulaşmıştır [51]. Su ürünleri yetiştiriciliği hızla gelişmesine rağmen ülkemizde kişi başına düşen yıllık balık eti tüketiminin oldukça düşük miktarda olduğu görülmektedir.
Kişi başına düşen yıllık balık eti tüketimimiz 2007 yılında $8,57 \mathrm{~kg}$ ile en yüksek seviyede iken 2013 yılında $6,307 \mathrm{~kg}$ ile en düşük seviyede seyretmiştir [50]. Oysa dünyada kişi başı su ürünleri tüketimi 2010 yılı verilerine göre $18,9 \mathrm{~kg}$, Çin dışında dünya su ürünleri tüketimi kişi başına $15,4 \mathrm{~kg}$, Avrupa'da ise $22,00 \mathrm{~kg}$ düzeyindedir [15]. Bu verilere göre dünya ortalamasını yakalamak için yaklaşık üç kat, Avrupa ortalamasını yakalamak için ise yaklaşık dört kat balık tüketmemiz gerekmektedir.

Zoonoz terimi genel olarak hayvanlardan insanlara geçebilen bir enfeksiyon olarak tanımlanmaktadır. Dünya Sağlık Örgütü (WHO) ise zoonoz teriminin tam anlamıyla omurgalı hayvanların doğal olarak enfeksiyonun sürmesi için gerekli olduğu vakaları tanımlamada kullanılması gerektiğini ve insanların rastlantısal konakçılar olduğunu bildirmektedir. Bu ikinci tanım insanlar ve hayvanlar tarafından ortak çevresel kaynaklardan ya da omurgasız organizmalardan bulaşan patojenler yani "ortak enfeksiyon" olarak adlandırılan kavram ile çelişmektedir. Gıda kaynaklı enfeksiyonlarda zoonoz enfeksiyonların bir formu olarak sınıflandırılmaktadır. Balık zoonozu olarak düşünülen birçok bakteri genellikle fakültatif patojenlerdir ve sıklıkla ortak 
enfeksiyon ya da kesin zoonoz olduğu arasında bir ayrım yapmak mümkün değildir [16]. Bu derlemede bakteriyel balık zoonozları tartışılırken hem balıklarda hem de insanlarda enfeksiyon oluşturan başlica bakteriyel zoonotik ajanlar dikkate alınmıştır.

\section{Gram Pozitif Bakteriler}

Clostridium botulinum: C. botulinum tüm dünyada tatlı su ve deniz balıklarının bağırsaklarında kommensal olarak bulunan, aynı zamanda çevresel sedimentlerde ve çürüyen organik maddelerde de bulunabilen mikroorganizmadır [16]. Etken anaerobik, Gram pozitif, spor oluşturan bir bakteridir ve dört farklı fenotipik gruba (I-IV) ayrılmaktadır. Bu gruplardan I ve II insanlar için patojeniktir. Ayrıca C. botulinum suşları serolojik olarak yedi farklı nörotoksin (A-G) üretmektedir. Bu toksin tipleri arasından insanlardaki salgınlarda en fazla karşılaşılan toksin tipleri tip $\mathrm{A}, \mathrm{B}, \mathrm{E}$ ve $\mathrm{F}$ iken, tip $\mathrm{C}$ ve $\mathrm{D}$ hayvanlardaki botulizm ile ilişsilendirilmektedir [8]. Balık tüketimiyle ilişkili olarak insanlarda ortaya çıkan birçok hastalık vakasından ise tip E toksininin sorumlu olduğu bildirilmektedir [16]. C. botulinum neurotoksin tip E'nin neden olduğu hastalık tablosu Amerika, Britanya ve Danimarka'da yetiştiriciliği yapılan salmonid balıklarda bildirilmiştir [5,12,21]. Bununla birlikte son yıllarda Güneydoğu Amerika'da kanal yayın balıklarında (Ictalurus punctatus) saptanan bir hastalık vakası viseral toksikozis olarak rapor edilmiştir [29]. Yapılan çalışmalar $C$. botulinum'un balıkların bağırsaklarında, yüzeylerinde, balık çiftliklerindeki sedimentlerde, balık ürünlerinde ve alglerde bulunabildiğini göstermektedir $[19,22,65]$.

İnsanlarda $C$. botulinum tip E toksin kaynak11 hastalıkların öyküsüne bakıldığında bulaşmanın sucul ortam, balık ve balık ürünlerinin tüketilmesi ile ilişkili olduğu görülmektedir. 2013 yılında Kanada'nın Ontario eyaletinde rapor edilen bir vakada iki yetişkin kadın tuzlanmış balık yedikten sonra hastaneye başvurmuşlar ve yapılan inceleme sonrası her iki hastanın serumlarında C. botulinum nörotoksin tip E tespit edilmiştir. Ayrıca bu hastalardan birinin mide sıvısından izolasyon yapılmıştır. Bu vakada aynı zamanda epidemiyolojik olarak bulaşma kaynağının belirlenmesi amacıyla marketlerden alınan gıda örneklerinden (tuzlanmış balık) etkenin izolasyonu yapılmış ve bu örneklerden de tip E toksini belirlenmiştir [59]. C. botulinum'un balıklardaki varlığ kontamine sucul ortam ile direkt temas ve $C$. botulinum sporlarının sedimentden veya kontamine besinlerden alınımı ile ilişkili olabilir. Balıkların işlemesi esnasında özellikle, uygun olmayan veya yetersiz 1sı uygulamaları son üründe tüm $C$. botulinum sporlarını yok etmede başarısız olabilmektedir. $\mathrm{Bu}$ gibi durumlarda $C$. botulinum halk sağlığı için bir tehdit oluşturabilir [41].

Erysipelothrix spp.: Erysipelothrix türleri arasinda E. rhusiopathiae, E. tonsillarum ve E. inopinata bulunmaktadır. Hayvanlarda E. rhusiopathiae'nın sebep olduğu hastalık "erysipelas" olarak bilinirken insanlarda hastalık "erysipeloid" olarak adlandırılmaktadır [16]. Erysipeloid aynı zamanda Rosenbach's hastalığ , Baker-Rosenbach hastalığ ve pseudoerysipelas olarak da isimlendirilmektedir [58]. E. rhusiopathiae (önceden E. insidiosa) küçük, Gram pozitif, çomak şeklinde, fakültatif aerobik, hareketsiz, spor oluşturmayan bir bakteridir $[58,63]$. Organizma her yerde bol olarak bulunmakta ve doğada (marin yerleşkeler dahil) uzun süreler boyunca persiste olarak kalabilmektedir. Etken birçok vahşi ve evcil hayvanda, kuşlarda ve balıklarda patojen veya kommensaldir. Domuz erysipelas'1 en yaygın olan ve en fazla ekonomik öneme sahip olan hastalıktır [63]. Chong ve ark., [6] iki farklı Avustralya yılan balığında (Anguilla reinhardtii ve A. australis) ortaya çıkan ve septisemi ile seyreden hastalık tablosunun E. rhusiopathiae kaynaklı olduğunu bildirmişler ve etkeni moleküler olarak PCR ile identifiye etmişlerdir. Bu vakada hastalığın strese bağlı ortaya çıan septisemik bir hastalık olduğu ve düşük mortalite ile seyrettiği rapor edilmiştir.

İnsanlarda E. rhusiopathiae nedenli enfeksiyonlar meslekle ilişkilendirilmiş, başlica kontamine hayvanlar, onların ürünleri veya atıkları veya toprak ile temas sonucunda ortaya çıktığg bildirilmiştir [63]. Hastalık başlıca hayvan yetiştiricileri, Veteriner Hekim, kesimhane çalışanı, kürkçü, kasap, balıkçı, ev kadını ve aşçılık gibi meslek gruplarında bulunmuştur [58]. E. rhusiopathiae kaynaklı insan enfeksiyonları (Fish rose) deri yaralarının kontaminasyonu ile olur ve genel olarak lokalize ağrıl1, s1nırlı selülitis, morarma ve ödem görülür. E. rhusiopathiae insanlarda sistemik enfeksiyon olarak nadir görülür, fakat sık olarak endocarditis ile ilişkilendirilir. İnsanlara E. rhusiopatiae kaynaklı zoonotik 
bulaşmanın (fish-handlers disease) balıkçılık sektöründe çalışanlar arasında meydana geldiği bildirilmektedir. Genetik bir kanit bulunmamakla birlikte, insanlardaki deri lezyonları ve E. rhusipathiae ile kolonize olmuş balıklardan elde edilen bağlantı bu bakterinin zoonotik bir ajan olduğu savını desteklemektedir [16].

Lactococcus garvieae: L. garvieae fakültatif anaerobik, hareketsiz, sporsuz, Gram pozitif oval kok şeklinde, alfa hemolitik mikroorganizmalardır. Etken ilk defa Büyük Britanya'da sığır mastitis vakasından izole edilmiş [56] sonraları ise, D grubu streptokoklar arasında en önemli balık patojeni olarak kabul görmüştür [16]. Balıklarda L. garvieae tarafindan meydana getirilen laktokokkozis enfeksiyonu, özellikle, tatlı su kültürlerindeki salmonid balıklar ve denizde yetiştiriciliği yapılan balık türlerinde yıkımlayıcı bir etkiye sahip olan bir tür streptokokkozis enfeksiyonu olarak tanımlanmaktadır [56].

L. garvieae'nın konakçı aralığı suda yaşayan türler ile sınırlı değildir. Etken aynı zamanda ineklerdeki subklinik meme içi enfeksiyonlardan, su buffalolarındaki subklinik mastitisten, tavuk etlerinden, çiğ inek sütünden, et ürünlerinden, domuz kanı işleyen endüstriyel mezbahanelerden ve kedi ve köpeklerin tonsillerinden izole edilmiştir [56]. Son yıllarda ise endocarditis, kolesistit ve diskospondilitis'e neden olan bir insan patojeni olarak tanımlanmaktadır [16]. İnsanlarda görülen enfeksiyonlar ile akuakülterde görülen salgınlar arasındaki ilişki açık bir şekilde ortaya konulamasa da, L. garvieae kaynaklı insan enfeksiyonları çiğ deniz ürünlerinin tüketilmesi ile ilişkilendirilmektedir. Wang ve ark., [60] insanlarda görülen bir L. garvieae enfeksiyonun çiğ balık tüketiminden kaynaklandığını ortaya koymuşlardır. $\mathrm{Bu}$ vakada enfeksiyonun özellikle balıklarda enfeksiyonun yüksek oranda görüldüğü yaz aylarında çiğ deniz ürünü tüketilmesiyle ortaya çıkmış olabileceğini bildirilmiştir. Epidemiyolojik incelemelerde 16S rDNA sekans analizi sonucuna göre hasta bireyden elde edilen izolat ile hastanın çiğ deniz ürünü yediği restorandan alınan mürekkep balığından elde edilen izolat arasında \%100 benzerlik belirlenmiştir. Bir başka vakada akut akalküloz kolesistitis enfeksiyonu bulanan bir hastanın safra kesesinden konvansiyonel kültür ve moleküler metotlar kullanılarak L. garvieae izolasyon ve identi- fikasyonu yapılmıştır. Bu vakadaki hastanın balıç̧ı olması, Kore'de gökkuşağı alabalığ1 yetiştiriciliği yapan bir işletmede çalışması ve ara sıra çiğ alabalık, sıklıkla çiğ deniz ürünü yediğinin bildirilmesi, enfeksiyonun kaynağının çiğ balık olabileceği yönünde güçlü şüphe oluşturmuştur [31].

Streptococcus spp.: Streptokoklar, Gram pozitif, hareketsiz, sporsuz, kapsülsüz ve aerobik mikroorganizmalardır [2]. Balıklardaki enfeksiyonlar genel olarak Lancefield grup B organizmaları $(S$. agalactiae) ya da Lancefield antijenlerini eksprese etmeyen $S$. iniae türlerinden kaynaklanmaktadır. $S$. agalactiae insanlarda neonatal sepsis, ineklerde mastitis etkenidir [16]. Japonya'da insan neonatal enfeksiyonlardan izole edilen $S$. agalactiae izolat ile Kuveyt'te balık ve yunuslardan izole edilen $S$. agalactiae izolatları arasında genetik yakınlık olduğu bildirilmiştir [13]. Yapılan bir başka çalışmada ise insan orijinli $S$. agalactiae izolatının deneysel olarak Nil tilapialarını (Oreochromis niloticus) enfekte ettiği belirlenmiş ve bu deneysel çalışma sonucunda grup B streptokokların memeliler ile balıklar arasındaki bulaşması ortaya konulmuştur [14].

S. iniae, orijinal olarak Amazon 1rmağ yunuslarından (Inia geofrensis) izole edilmiştir [16]. Weinstein ve ark. [64] Toronto'da bir hastalık salgınında $S$. iniae'yı zoonoz enfeksiyon olarak identifiye etmişlerdir. Bu vakada dokuz hastada çiğ balık ile temasa bağlı olarak ortaya çıkan selülitis, bir hastada ayrica endokarditis, meningitis ve artiritis saptanmıştır. Araştırmacılar PFGE metodu ile 9 hastadan izole edilen S. iniae şuşlarının 1993 yılında Virginia' da yerel balık marketlerindeki tilapia balıklarından elde edilen $S$. iniae şuşları ile eşleştiğini bildirmişlerdir. $S$. iniae kaynaklı zoonotik enfeksiyonlar Güneydoğu Asya, Kanada ve Hon Kong'da öncelikli olarak balık işleme esnasında ve canlı balıklar ile temas ile ilişsilendirilerek rapor edilmiştir $[32,34]$.

Nocardia spp.: Nocardia etkenleri Gram pozitif, zayıf asidorezistans özellikte aerobik, sporsuz, kokoid ve/veya küçük çomakçık şeklinde görülen mikroorganizmalardır [2]. Doğada yaygın olarak bulunan Nocardia türleri, insanlarda pulmoner, kutanöz, merkezi sinir sistemi ve sistemik nokardiyoz gibi çeşitli enfeksiyonlara neden olabilmekte ve sıklıkla bağışıklığı baskılanmış hastalarda belirtiler meydana gelmektedir [35,52]. İnsanlarda Nocardia 
spp. enfeksiyonları öncelikli olarak $N$. asteroides ve yakın akraba türleri $N$. farcinica, $N$. brasiliensis ve $N$. otitidiscaviarum ile ilişkilendirilmesine rağmen [35] ülkemizde yapılan bir çalışmada klinik örneklerden izole edilen 45 suşun çoğunluğunun $N$. cyriacigeorgica (n:26, \%57,8) olduğu, bunu $N$. farcinica (n:12, \%26,7), N. otitiscaviarum (n:4, \%8,9), $N$. asteroides (n:1, \%2,2), N. neocaledoniensis (n:1, $\% 2,2)$ ve $N$. abscessus'un (n:1, \%2,2) takip ettiği saptanmıştır [52]. Balıklarda enfeksiyona başlıca $N$. asteroides ve $N$. seriolae türleri neden olmaktadır [2]. Ancak balık ve insan izolatları arasında henüz epidemiyolojik veya genetik bir ilişki saptanamad1ğ1 bildirilmiştir [16].

Mycobacterium spp.: Mycobacterium genusunda yer alan $M$. tuberculosis kompleksi ve $M$. leprae dışında kalan tüm türler tüberküloz dışı mikobakteriler (Nontuberculous mycobacteria, NTM) olarak tanımlanmaktadır [37]. Genel olarak çoğu mikobakter plemorfik Gram pozitif, asit fast, aerobik, hareketsiz ve çomak şeklinde mikroorganizmalardır [17, 23]. 140'dan fazla NTM türü rapor edilmiş olup, bu türlerin yaklaşık 25'i NTM hastalıkları ile güçlü bir şekilde ilişkilendirilmektedir. Geri kalan türler ise nadir olarak çevresel örneklerde karş1laşılan türlerdir [54]. Balıklarda tüberküloz, başta M. marinum, $M$. fortuitum ve $M$. chelonae olmak üzere $M$. absscessus, $M$. gordonae, $M$. haemophilum, $M$. interjectum, $M$. montefiorense, $M$. pseudoshottsii, M. scrofulaceum, M. shottsii, M. szulgai ve M. similae gibi birçok mikobakteriyel tür tarafindan meydana getirilmektedir [17,23].

NTM'ler tipik olarak toprak ve suyun yanı sira arıtılmış sularda da yaşayan çevresel organizmalardır. Genel olarak insanlar için düşük patojeniteye sahip olmalarına rağmen, sıklıkla akciğer hastalıklarına, takiben özellikle çocuklarda lenfadenitis'e, M. marinum tarafindan meydana getirilen deri hastalıklarına, bağışık sistemi baskılanmış bireylerde diğer ekstrapulmoner hastalıklara veya yaygın sistemik enfeksiyonlara neden olabilmektedir [54]. İnsanlarda balık ya da su kaynaklı mikobakteriyel enfeksiyonlar çoğunlukla, ekstremitelerde süperfasiyal granulamatöz bir yangı formu şeklinde görülür. Ancak lezyonlar daha derin dokulara inebilir ve tenosynovitis, bursitis, artiritis ve osteomyelitis'e neden olabilir [33]. Patojenik balık mikobakterileri ile ilişkili insan enfeksiyonlarının genellikle, yara ve deri sıyrıklarının kontamine suya maruz kalması yoluyla bulaştığı bildirilmektedir [43]. Yine akvaryum balıklarında ve balık sahiplerinde ayn VNTR (variable number tandem repeat) profiline sahip $M$. marinum suşlarının izole edilmiş olması akvaryumların olası enfeksiyon kaynağı olabileceğini göstermektedir [47]. Pekin'de yapılan bir çalışmada NTM kaynaklı sporadik deri enfeksiyonlarında en yaygın türün M. marinum (37 vakanın 30'unda) olduğu ortaya konmuştur [28]. Yine bir başka çalışmada Milan'da hastalık öyküsünde balık tanklarıyla düzenli olarak fiziksel teması olduğu bildirilen sporotrichoid deri enfeksiyonu gözlenen 14 hastadan M. marinum izole edilmiştir [57].

1984-2014 y1lları arasında Orta Doğu ülkelerinde yapılmış 96 çalışmada 1751 NTM şuşu izole edilmiştir. Bunların 1084'ü klinik örneklerden, 619'u çevresel örneklerden, 48'i ise olgu bildirimlerinden elde edilmiştir. Bu tarihler arasında ülkeler bazında İran'dan 34, Türkiye'den 21, Suudi Arabistan'dan 18, Lübnan'dan 5, Katar'dan 4, Pakistan'dan 4, Irak'tan 3, Misir'dan 2, Bahreyn'den 2, Kuveyt'ten 2, Umman'dan 1 bildirim yapılmıştır. Hizlı üreyen mikobakteriyel türler arasında yer alan M. fortuitum klinik ve çevresel örneklerden sırasıyla $\% 60,1$ ve $\% 46,7$ izoloasyon oranıla en yaygın tür olarak belirlenmiştir [55].

\section{Gram Negatif Bakteriler}

Aeromonas spp.: Aeromanas cinsi, akuatik çevrenin normal faunasında bulunan fakültatif anaerobik, oksidaz pozitif, Gram negatif bakterilerdir. Aeromonas cinsinin bugünkü sinıflandırması DNA-DNA hibridizasyonuna ve $16 \mathrm{~S}$ ribozomal DNA ile ilgili çalışmalara dayanmaktadır. Bu cins içerisinde 17 Hibridizasyon Grubu (HG) ve gruplara dahil mezofilik ve psikrofilik olarak bilinen hareketli (tek, polar flagella) ve hareketsiz türler bulunmaktadır. Aeromonaslar hayvan ve insanların bağırsak florasında gastrointestinal hastalık tablosu göstererek veya göstermeden bulunmaktadırlar. Bazı türleri insanlar için patojendir. İnsanlarda meydana gelen hastalıkların birçoğu HG-1 (A. hydrophila), HG-4 (A. caviae), HG-8 (A. veronii), HG-9 (A. jandaei), HG-10 (A. veronii biovar veronii), HG-12 (A. schubertii) veya HG-14 (A. trota) gruplarında bulunan türlerden ileri gelmektedir. İnsanlarda hastalık oluşturma yeteneğinde olan bu hibridizasyon grup- 
larındaki türlerin oranı ise bilinmemektedir [39]. İnsanlarda hastalık oluşturan aeromonaslar septisemi, yara enfeksiyonu, menenjit, peritonit ve karaciğer fonksiyon bozukluğu gibi çok değişik enfeksiyonlar ile ortaya çıkabilmektedir. Bazı türler ise enterotoksin üretmesi nedeniyle gastrointestinal sistem hastalıklarına neden olabilmektedirler [27]. Özellikle, $A$. hydrophila kaynaklı hastalıkların büyük bir kısmı su ürünleri veya uzun süreli dondurulmuş tüketime hazır gıdalar ile ilişkilendirilmektedir [10]. Bununla birlikte hastalık etkenlerinin direkt olarak canlı balıklardan insanlara geçişi ile ilgili bilgiler sınırlıdır. Yapılan bir çalışmada kistik fibrözlü 11 aylık bir erkek çocuğunun öksürük sıvabından Pseudomonas aeruginosa ve $A$. hydrophila izole edilmiş ve bu vakada izole edilen $A$. hydrophila suşunun çocuğun evinde bulunan akvaryumdan aerosol yolla bulaştığı sonucuna varılmıştır. Akvaryumun evden çıkarılması ile etken bir daha izole edilmemiştir [9].

Edwardsiella spp.: Edwardsiella genusu Enterobacteriaceae familyasının bir üyesidir ve bu genus içerisinde yer alan türler Gram negatif, genellikle hareketli, fakültatif anaerobik, küçük düzgün çomak şeklinde mikroorganizmalardır [44]. Edwardsiella genusu içerisinde E. ictaluri, E. tarda ve E. hoshinae gibi balık, insan, kuş ve sürüngenlerden izole edilmiş türler bulunmaktadır [16,40,44]. Ayr1ca son yıllarda daha önce hasta balıklardan E. tarda olarak izole ve identifiye edilmiş olan suşlarının fenotipik ve genetik çalışmalar sonrası E. tarda türüne ait olmadıkları belirlenmiş ve bu suşlar Edwardsiella genusuna ait yeni bir tür, E. piscicida, olarak önerilmiştir [1]. E. ictaluri kedi balıklarının önemli patojenlerinden bir tanesidir ve enterik septisemiye neden olur [18]. Etkenin insanlar1 enfekte ettiği bilinmemektedir [16]. E. hoshinae genel olarak kuşlar ve sürüngenlerden izole edilir. Aynı zamanda insan dışkısından izole edilmesine rağmen insan ve hayvan patojeni olarak rolü kesin değildir [24]. E. tarda başlıca yılan balıkları ve kedi balıkları olmak üzere tatlı ve tuzlu sularda bulunan birçok balık türünü enfekte etmesine rağmen konakçı aralığ sadece balıklarla sınırlı değildir. Etkenin reptilleri, kuşları, deniz memelilerini, büyük baş hayvanları, domuzları enfekte edebileceği bildirilmektedir. $E$. tarda çoğu kez akuatik hayvanların normal intestinal florasının bir parçasıdır. Etken aynı zamanda insanlarda birçok farklı klinik tablo ile ilişkilendi- rilmektedir [44]. E. tarda'nın neden olduğu insan enfeksiyonları primer olarak gastroenteritis ile karakterizedir. Bununla birlikte septisemi ve menenjit gibi sistemik hastalıklar ve yara enfeksiyonları da görülmektedir [7, 25]. E. tarda asemptomatik olarak insanların dışkısında bulunabilmektedir [25]. Hastalık için risk faktörleri arasında akuatik çevre ve buna bağlı olarak balıklar, sürüngenler ve amfibiler yer almaktadır. E. tarda çeşitli deniz ve tatlı su balıklarında Edwardsiella septicaemia olarak adlandırılan hemorajik ve nekrotik hastalığı, yılan balıklarında kırmızı hastalığına (red disease) neden olur [16]. E. tarda'nın balıklardan insanlara direkt olarak geçişiyle ilgili birkaç rapor vardır. Bunlardan bir tanesinde Belçikalı 2 aylık bir bebekteki diyare tablosu E. tarda ile ilişkilendirilmiş ve etken hasta ile aynı evde bulunan tropikal akvaryumdaki balıktan izole edilmiştir. Bu vakada balıkların hastalık için rezervuar olarak görev yaptığı bildirilmiştir [53].

Vibrio spp.: Vibrionaceae familyası içerisinde yer alan Vibriolar Gram negatif, fakültatif anaerobik, genellikle hareketli, düz veya hafif kıvrık çomakcıklar şeklinde mikroorganizmalardır [2]. Vibrio türleri balıklarda ve sucul ortamda yaygın bir dağılım göstermektedir. Çeşitli Vibrio türleri hem vahşi hem de kültür balıklarında ciddi hastalıklara neden olabilirler. Balıklarda patojenik türler arasında $V$. ordalii (salmonidlerde septisemi), $V$. anguillarum (yılan balıklarında red pest), V. salmonicida (soğuk su vibriozisi), V. vulnificus (Avrupa yılan baliklarında sıcak su vibriozisi), $V$. viscous ve $V$. wodanis (Atlantik somonlarında kış ülser hastalığı) yer almaktadır [16,41].

Vibrio türleri doğada yaygın olarak bulunmas1 nedeniyle aynı zamanda balık ve kabuklu deniz ürünlerinin deri, solungaç ve intestinal kanalında gözlenmektedir [41]. Vibrio türleri arasında, V. cholerae, $V$. vulnificus ve $V$. parahemolyticus türleri insanlardaki vibriozis vakalarında görülmekte ve bu türler balık ve kabuklu deniz ürünlerinin tüketimi ile ilişkilendirilmektedir. Bu türler arasında insan sağlığı açısından en önemli olanı $V$. cholerae, özellikle de kolera toksini üreten suşlarıdır [16,41]. $V$. cholerae'nın 200'den fazla serogrubu bulunmaktadir ve bu serogruplardan sadece O1 ve O139 kolera hastalığının etiyolojik ajanıdır. Diğer serogruplara dahil suşlar genellikle non-O1/non-O139 suşlar olarak ifade edilmektedir ve tüm dünyada akuatik 
ekosistemin normal mikrobiyotasının parçasıdır. Bu gruplara dahil $V$. cholerae suşları kulak ve yara enfeksiyonu gibi lokal enfeksiyonların yanı sıra gastroenteritise neden olabilmektedir [20]. V. cholerae'nın balıklarda hastalık oluşturduğuna dair ise sınırlı sayıda çalışma bulunmaktadır [30]. V. vulnificus ve $V$. parahemolyticus türleri insan vibriozisi ile daha sık olarak ilişkilendirilmekte ve genellikle yetersiz işlem görmüş balık ya da balıkçılık ürünlerinin tüketilmesi ile hastalığın meydana geldiği bildirilmektedir [41]. Bu bakteriler insanlarda yara enfeksiyonu, septisemi ve gastroenteritis'e neden olmaktadır. Bu etkenlerden $V$. parahaemolyticus gida kaynaklı bir zoonoz olup, insanlarda kontamine g1daların özellikle, istiridye gibi yumuşakçaların ağız yoluyla alınmasıyla hastalık oluşturmaktadır [11]. Balıklarda ise $V$. parahemolyticus kaynaklı mortalite bildirimi İspanyol dişli sazanlarında (Aphanius iberus) yapılmıştır [3]. V. vulnificus ise başlıca yılan balıklarında hastalığa neden olmaktadır. $V$. vulnificus'un üç biyotipi (biyotip 1, 2 ve 3) tanımlanmıştır. Biyotip 1 başlıca sulardan ve insanlardan, biyotip 2 ise başlıca balıklardan ve insanlardan izole edilmiş̧tir. Biyotip 2 sonraları balıklar için enfeksiyöz olan serovar A, E ve I'ya ayrılmıştır, ancak bu serovarlardan sadece serovar E'nin zoonotik potansiyele sahip olduğu görülmektedir. Biyotip 3 insanlarda septisemi ve yara enfeksiyonlarından izole edilmiştir. Ancak bu biyotipin biyotip 1 ve 2 arasında hibrit bir biyotip olduğu kabul edilmektedir [16]. $\mathrm{V}$. vulnificus biyotip 2, serovar E insan izolatının balık suşları için identikal virulens plazmidini taşıdığının saptanmas1 [61] ve sekans analizi sonucu insan ve yılan balığ ${ }_{1}$ izolatlarınına ait virulens genlerinin ( $v$ hA ve $v v p$ ) dizilimlerinin örtüşmesi [45] balık ve insan izolatlar arasındaki olası geçişin kanıtları arasinda yer almaktadır.

V. cholerae, $V$. vulnificus ve $V$. parahemolyticus dışında kalan diğer türler; Grimontia (=Vibrio) hollisae, Photobacterium (=Vibrio) damselae subsp. damselae, V. alginolyticus, V. fluvialis, V. furnissii, $V$. harveyi ( $=V$. carchariae), $V$. metschnikovii ve $V$. mimicus düşük risk grubunda yer almaktadırlar ve nadir olarak da insanlarda özellikle de gastroenteritis ve yara enfeksiyonlarından izole edilmektedir $[4,16]$.

Plesiomonas shigelloides: $P$. shigelloides Gram negatif, hareketli ve oksidaz pozitif uzun düz çomak şeklinde mikroorganizmalardır. Etken Plesiomonas genusunun tek üyesidir ve aynı zamanda Enterobacteriaceae familyasında oksidaz pozitif olan tek üyedir [48]. P. shigelloides tüm dünyada yaygın bir dağılıma sahiptir. Başlıca tatlı sularda (havuz, akarsu ve göller) bulunmasına rağmen dere ağzı ve deniz ortamında da bulunmaktadır. $P$. shigelloides çeşitli balık türlerinden, deniz kabuklularından, kuşlardan ve insanlardan izole edilmiştir. Aynı zamanda insan mikrobiyotasının bir üyesidir. Tropikal ve subtropikal bölgelerde $P$. shigelloides enfeksiyonu büyük çoğunlukla yaz aylarında meydana gelir [42]. İnsanlarda başlica intestinal hastalıklar olmak üzere yüksek mortalite oranı ile seyreden sepsis ve menengitis gibi daha yaygın görülen ekstraintestinal hastalıklara neden olan önemli bir patojendir [48]. İnsanlardan rapor edilen enfeksiyon vakalarının büyük çoğunluğunun başlıca az pişmiş ya da çiğ istiridye, balık, deniz tarağı ve karides gibi kontamine deniz ürünlerinin alımı ile veya içerisinde Plesiomonas bulunan içilebilir sulardan kaynaklandığı düşünülmektedir [26]. Son yıllarda P. shigelloides 'in tatlı sularda yetiştiriciliği yapılan farklı balık türlerinde enfeksiyona neden olduğuna dair bildirimlerin sayısında dikkate değer bir artış görülmektedir $[38,62]$. Bu vakaların birinde mersin balıklarında \%60'a varan kümülatif mortalite bildirilmiştir [62].

Pseudomonas spp.: Pseudomonaceae familyasinda yer alan türler, Gram negatif, hareketli, aerobik ve fakültatif anaerobik ve çomak şeklinde mikroorganizmalardır [2]. Bu mikroorganizmalar tüm dünyada su ve toprakta yaygın olarak bulunurlar [16]. Balıklarda hastalık yapan Pseudomonas türleri arasinda $P$. anguiliseptica ve $P$. fluorescens en s1k izole edilen türlerdir [2]. P. anguiliseptica başlıca yılan balıklarında olmak üzere çipura, Baltık ringası ve morina balıklarında peteşiyel hemoraji ile karakterize hastalığa neden olmaktadır. P. fluorescens ise gümüş sazanı, Japon balığı, kadife balığ1, ot sazan1, siyah sazan ve gökkuşağı alabalığ1 gibi bir çok bal1k türünde görülen nekrotik ve hemorajik hastal1ğın etkenidir [4]. P. aeruginosa insanlarda pnömoni etkeni olarak iyi bilinmektedir ve balıkların viseral dokularından izole edilmiştir [36]. P. fluorescens' in de insanlarda kistik fibrozis vakalarından izole edildiğine dair veriler bulunmaktadır [46]. 


\section{Kaynaklar}

1. Abayneh T, Colquhoun DJ, Sørum H, (2013). Edwardsiella piscicida sp. nov., a novel species pathogenic to fish. J Appl Microbiol. 114, 644-654.

2. Arda M, Seçer S, Sarıeyyüpoğlu M, (2005). Balık Hastalıkları. II. Baskı (Genişletilmiş). Ankara: Medisan Yayın Serisi: 61.p.70, 96, 99, 105

3. Austin B, Austin DA. (2007) Bacterial fish pathogens, Diseases of farmed and wild fish. Springer-Praxis Publishing, Chichester, UK.

4. Austin B, (2010). Vibrios as causal agents of zoonoses. Vet Microbiol. 140, 310-317.

5. Cann DC, Taylor LY, (1982). An outbreak of botulism in rainbow trout, Salmo gairdneri Richardson, farmed in Britain. J Fish Dis. 5, 393-399.

6. Chong, RS-M, Shinwari MW, Amigh MJ, Aravena-Roman M, Riley TV, (2015). First report of Erysipelothrix rhusiopathiae-associated septicaemia and histologic changes in cultured Australian eels, Anguilla reinhardtii (Steindachner, 1867) and A. australis (Richardson, 1841). J Fish Dis. 38, 839-847.

7. Clarridge JE, Musher DM, Fainstein V, Wallace RJJr, (1980). Extraintestinal human infection caused by Edwardsiella tarda. J Clin Microbiol. 11, 511-514.

8. Collins MD, East AK, (1998). Phylogeny and taxonomy of the foodborne pathogen Clostridium botulinum and its neurotoxins. J Appl Microbiol. 84, 5-17.

9. Cremonesini D, Thomson A, (2008). Lung colonization with Aeromonas hydrophila in cystic fibrosis believed to have come from a tropical fish tank. J R Soc Med. 101, S44-S45.

10. Daskalov H, (2006). The importance of Aeromonas hydrophila in food safety. Food Control. 17(6), 474-483.

11. Drake SL, DePaola A, Jaykus L.-A, (2007). An overview of Vibrio vulnificus and Vibrio parahaemolyticus. Comp Rev Food Sci Food Safe. 6, 120-144.

12. Eklund MW, Poysky FT, Peterson ME, Peck, LW, Brunson WD, (1984). Type E botulism in salmonids and conditions contributing to outbreaks. Aquaculture. 41, 293-309.

13. Evans JJ, Bohnsack JF, Klesius PH, Whiting AA, Garcia JC, Shoemaker CA, Takahashi S, (2008). Phylogenetic relationships among Streptococcus agalactiae isolated from piscine, dolphin, bovine and human sources: a dolphin and piscine lineage associated with a fish epidemic in Kuwait is also associated with human neonatal infections in Japan. $\mathrm{J}$ Med Microbiol. 57, 1369-1376.

14. Evans JJ, Klesius PH, Pasnik DJ, Bohnsack JF, (2009). Human Streptococcus agalactiae isolate in Nile Tilapia (Oreochromis niloticus). Emerg Infect Dis. 15(5), 774-776.

15. FAO, (2014). The State of World Fisheries and Aquaculture, Rome, Italy, 62-63 pp.

16. Gauthier DT, (2015). Bacterial zoonoses of fishes: a review and appraisal of evidence for linkages between fish and human infections. Vet J. 203(1), 27-35.

17. Gauthier DT. Martha WR, (2009). Mycobacteriosis in fishes: a review. Vet J. 180, 33-47.
18. Hawke J, McWhorter A, Steigerwalt A, Brenner D, (1981). Edwardsiella ictaluri sp. nov., the causative agent of enteric septicemia of catfish. Int J Syst Bacteriol. 31, 396-400.

19. Hielm S, Björkroth J, Hyytia E, Korkeala H, (1998). Prevalence of Clostridium botulinum in Finnish trout farms: pulsed-field gel electrophoresis typing reveals extensive genetic diversity among type E isolates. Appl Environ Microbiol. 64(11), 4161-4167.

20. Huehn S, Eichhornb C, Urmersbacha S, Breidenbachc J, Bechlarsd S, Bierd N, Altera T, Bartelte E, Frankc C, Oberheitmannf B, Gunzerb F, Brennholtg N, Böerg S, Appeld B, Dieckmannd R, Strauch E, (2014). Pathogenic vibrios in environmental, seafood and clinical sources in Germany. Int J Med Microbiol. 304(7), 843-850.

21. Huss HH, Eskildsen U, (1974). Botulism in farmed trout caused by Clostridium botulinum type E; a preliminary report. Nord Vet Med. 26, 733-738.

22. Hyytia E, Hielm S, Björkroth J, Korkeala H, (1999). Biodiversity of Clostridium botulinumType $E$ Strains Isolated from fish and fishery products. Appl Environ Microbiol. 65(5), 2057-2064.

23. Jacobs JM, Stine CB, Baya AM, Kent ML, (2009). A review of mycobacteriosis in marine fish. J Fish Dis. 32(2), 119-130.

24. Janda JM, Abbott SL, Kroske-Bystrom S, Cheung WK, Powers C, Kokka RP, Tamura K, (1991). Pathogenic properties of Edwardsiella species. J Clin Microbiol. 29, 19972001.

25. Janda JM, Abbott SL, (1993). Infections associated with the genus Edwardsiella: the role of Edwardsiella tarda in human disease. Clin Infect Dis. 17, 742-748.

26. Janda JM, Abbott SL, (1999). Unusual food-borne pathogens. Listeria monocytogenes, Aeromonas, Plesiomonas, and Edwardsiella species. Clin Lab Med. 19, 553-582.

27. Janda JM, Abbott SL, (2010). The genus Aeromonas: Taxonomy, pathogenicity, and infection. Clin Microbiol Rev. 23, 35-73.

28. Jin J, Jia J, Ding XL, Chen X, Sun QM, Xu JN, Xue CH, DU J, Cai L, Zhang JZ, (2015). Sporadic cutaneous infections due to nontuberculous mycobacteria: a retrospective study of 37 cases. Beijing Da Xue Xue Bao. 47(6), 939-944.

29. Khoo LH, Goodwin AE, Wise DJ, Holmes WE, Hanson LA, Steadman JM, Mc Intyre LM, Gaunt PS, (2011). The pathology associated with visceral toxicosis of catfish. J Vet Diagn Invest. 23(6), 1217-1221.

30. Kiiyukia C, Nakajima A, Nakai T, Muroga K, Kawakami H, Hashimoto H, (1992). Vibrio cholerae non-O1 isolated from ayu fish (Plecoglossus altivelis) in Japan. Appl Environ Microbiol. 58(9), 3078-3082.

31. Kim JH, Go J, Cho CR, Kim JI, Lee MS, Park SC, (2013). First report of human acute acalculous cholecystitis caused by the fish pathogen Lactococcus garvieae. J Clin Microbiol. 51, 712-714.

32. Koh TH, Kurup A, Chen J, (2004). Streptococcus iniae discitis in Singapore. Emerg Infect Dis. 10, 1694-1696.

33. Lahey T, (2003). Invasive Mycobacterium marinum infections. Emerg Infec Dis. 9, 1496-1498. 
34. Lau SKP, Woo PCY, Tse H, Leung K-W, Wong SSY, Yuen K-Y, (2003). Invasive Streptococcus iniae infections outside North America. J Clin Microbiol. 41, 1004-1009.

35. Lederman ER, Crum NF, (2004). A case series and focused review of nocardiosis. Medicine. 83, 300-313.

36. Leung CK, Huang YW, Pancorbo OC, (1992). Bacterial pathogens and indicators in catfish and pond environments. J Food Protect. 55, 424-427.

37. Li J, Chong AH, O'Keefe R, Johnson PD, (2014). The fish tank strikes again: Metachronous nontuberculous mycobacterial skin infection in an immunosuppressed host. Australas J Dermatol. 55(4), e77-e79.

38. Liu Z, Ke X, Lu M, Gao F, Cao J, Zhu H, Wang M, (2015). Identification and pathological observation of a pathogenic Plesiomonas shigelloides strain isolated from cultured tilapia (Oreochromis niloticus). Wei Sheng Wu Xue Bao. 55(1), 96-106.

39. Martin-Carnahan E, Joseph WS, (2005). Aeromonas. In: DJ Brenner, NR Krieg, JT Staley, GM Garrity (Ed), Bergey's Manual of Systematic Bacteriology, 2nd Ed., Vol. 2, Springer-Verlag, New York. p.556-578.

40. Mohanty BR, Sahoo PK, (2007). Edwardsiellosis in fish: a brief review. J Biosci. 32, 1331-134.

41. Novoslavskij A, Terentjeva M, Eizenberga I, Valciņa O, Bartkevičs V, Bērziņš A, (2016). Major foodborne pathogens in fish and fish products: a review. Ann Microbiol. 66, $1-15$.

42. Pence MA, (2016). Wound infection with Plesiomonas shigelloides following a freshwater injury. J. Clin Microbiol. 54(5), 1180-1182.

43. Petrini B, (2006). Mycobacterium marinum: Ubiquitous agent of waterborne granulomatous skin infections. Eur J Clin Microbiol Infect Dis. 25, 609-613.

44. Plumb JA, (1999). Edwardsiella Septicemias. In: Fish Diseases and Disorders Volume 3. Viral, Bacterial and Fungal İnfections. Ed.: P.T.K. Woo, D.W. Bruno, CAB International, New York, USA. p.479-521.

45. Roig FJ, Amaro C, (2009). Plasmid diversity in Vibrio vulnificus biotypes. Microbiology (Reading, England). 155, 489-497.

46. Scales BS, Erb-Downward JR, Huffnagle IM, LiPuma JJ, Huffnagle GB, (2015). Draft Genome Sequences of Seven Pseudomonas fluorescens Subclade III Strains Isolated from Cystic Fibrosis Patients. Genome Announc. 3(1), e01285-14.

47. Slany M, Jezek P, Bodnarova M, (2013). Fish tank granuloma caused by Mycobacterium marinum in two aquarists: two case reports. Biomed Res Int. 2013:161329, 4 pages.

48. Stock I, (2004). Plesiomonas shigelloides: an emerging pathogen with unusual properties. Rev Med Microbiol. 15, 129-139.

49. Türel M, (2002). Su Ürünleri Yetiştiricilik Alt Sektöründe Planlama. Yüksek Lisans Tezi. Ege Üniversitesi Fen Bilimleri Enstitüsü, İzmir.

50. Türkiye İstatistik Kurumu (TUİK), (2013). Su Ürünleri Istatistikleri 2012, Türkiye İstatistik Kurumu Matbaas1, Ankara.
51. Türkiye İstatistik Kurumu (TUİK), (2014). Türkiye Su Ürünleri İstatistikleri 2014, internet erişimi: http://www tuik.gov.tr/PreTablo.do?alt_id=1005, 23.05.2016

52. Uner MC, Hascelik G, Mustak HK, (2016). 16S rRNA gen dizi analizi ile tanımlanan klinik Nocardia izolatlarının antimikrobiyal duyarlılıkları. Mikrobiyol Bul. 50(1), 11-20.

53. Vandepitte J, Lemmens P, Swert L, (1983). Human Edwardsiellosis traced to ornamental fish. J Clin Microbiol. 17, 165-167.

54. van Ingen J, (2013). Diagnosis of nontuberculous mycobacterial infections. Semin Respir Crit Care Med. 34(1), 103-109.

55. Velayati AA, Rahideh S, Nezhad ZD, Farnia P, Mirsaeidi M, (2015). Nontuberculous mycobacteria in Middle East: Current situation and future challenges. Int J Mycobacteriol. 4(1), 7-17.

56. Vendrell D, Balcazar JL, Ruiz-Zarzuela I, de Blas I, Girones O, Muzquiz JL, (2006). Lactococcus garvieae in fish: A review. Comp Immun Microbiol Infect Dis. 29, 177-198.

Veraldi S, Çuka E, Nazzaro G, (2014). Treatment of sporotrichoid fish tank granuloma with pulsed clarithromycin. Dermatology. 229, 83-87.

57. Veraldi S, Girgenti V, Dassoni F, Gianotti R, (2009). Erysipeloid: a review. Clin Exp Dermatol. 34(8), 859-862.

58. Walton RN, Clemens A, Chung J, Moore S, Wharton D, Haydu L, deVilla E, Sanders G, Bussey J, Richardson D, Austin JW, (2014). Outbreak of type E foodborne botulism linked to traditionally prepared salted fish in Ontario, Canada. Foodborne Pathog Dis. 11(10), 830-834.

59. Wang CY, Shie HS, Chen SC, Huang JP, Hsieh IC, Wen MS, Lin FC, Wu D, (2007). Lactococcus garvieae infections in humans: possible association with aquaculture outbreaks. Int J Clin Pract. 61, 68-73.

60. Wang J, Sasaki T, Maehara Y, Nakao H, Tsuchiya T, Miyoshi S-I, (2008). Variation of extracellular proteases produced by Vibrio vulnificus clinical isolates: Genetic diversity of the metalloprotease gene (vvp), and serine protease secretion by vvp-negative strains. Microb Pathog. 44, 494-500.

61. Wang X, Xu L, Cao H, Wang J, Wang S, (2013). Identification and drug sensitivity of a Plesiomonas shigelloides isolated from diseased sturgeons. Wei Sheng Wu Xue Bao. 53(7), 723-729.

62. Wang Q, Chang BJ, Riley TV, (2010). Erysipelothrix rhusiopathiae. Vet Microbiol. 140(3), 405-417.

63. Weinstein MR, Litt M, Kertesz DA, Wyper P, Rose D, Coulter M, McGeer A, Facklam R, Ostach C, Willey BM, Borczyk A, Low DE, (1997). Invasive infections due to a fish pathogen, Streptococcus iniae. N Engl J Med. 337, 589-94.

64. Wijesinghe RU, Oster RJ, Haack SK, Fogarty LR, Tucker TR, Riley SC, (2015). Spatial, temporal, and matrix variability of Clostridium botulinum Type E toxin gene distribution at great lakes beaches. Appl Environ Microbiol. 81(13), 4306-4315. 